\title{
Characterization and Distribution of Medicine Vendors in Nigeria: A study of Lagos and Kaduna States.
}

\section{Babajide Oluseyi Daini ( $\sim$ Dainimichael@yahoo.com )}

Population Council, Nigeria https://orcid.org/0000-0002-4927-2862

\section{Emeka Okafor}

IntegratE, Abuja

\section{Sikiru Baruwa}

Population Council

Oluwafunmito Adeyanju

PharmAccess

Jennifer Anyanti

Society for Family Health

\section{Research}

Keywords: Family Planning, Health Workers, Health Training, PPMVs, Stocking, and Task Shifting

Posted Date: August 4th, 2020

DOI: https://doi.org/10.21203/rs.3.rs-49608/v1

License: (c) (i) This work is licensed under a Creative Commons Attribution 4.0 International License. Read Full License 


\section{Abstract \\ Background}

In 2014, Nigeria issued the task-shifting/sharing policy for essential health services, which aimed to fill the human resource gap and improve the delivery of health services across the country. This study focuses on the characteristics, spread, and Family planning (FP) stocking practices of medicine vendors in Lagos and Kaduna, assessing the influence of health training on the provision and stocking of FP services and commodities by vendors.

\section{Methods}

We conducted a census of all patent and proprietary medicine vendor (PPMV) shops and followed up with a facility assessment among $10 \%$ of the mapped shops; utilizing an interviewer-administered questionnaire. Bivariate analysis was conducted using the chi-square test, and multiple logistic regression was used to estimate the adjusted odds ratio (OR) and confidence intervals (C.I) for the test of significance in the study.

\section{Results}

8,318 medicine shops were censused (76.2\% Urban). There were 39 shops per 100,000 population in both states on average. About half (50.9\%) were manned by a medicine vendor without assistance, $25.7 \%$ claimed to provide FP services to $>2$ clients per week, and $11.4 \%$ were not registered with the regulatory body or any trade association. Also, $28.2 \%$ of vendors reported formal health training; with $56.3 \%$ of these health trained vendors relatively new in the business, opening within the last five years. Vendors utilized open drug markets as the major source of supply for FP products. Health training significantly increased the stocking of FP products and inhibited the utilization of open drug markets.

\section{Conclusion}

PPMVs have continued to grow progressively in the last five years, becoming the most proximal health facility for potential clients for different health services (especially FP services) across both Northern and Southern Nigeria. Now comprised of a considerable mass of health trained personnel, able to deliver high-quality health services and complement existing healthcare infrastructure, if trained. However, restrictions on services within the PPMV shop and lack of access to quality health commodities and consumables have resulted in poor practices among PPMVs. There is therefore a need to identify, train, and provide innovative means of improving access to qualityassured products for this group of health workers.

\section{Introduction}

Across several low and middle-income countries (LMICs), national health systems have been functioning suboptimally due to recurring challenges within the health sector, with this particularly affecting the delivery of accessible and affordable healthcare services [1]. The health system, in most cases, is synonymous with publicly owned health facilities, with several important private and non-state actors being downplayed [2]. The functional 
capacities of the health system in these settings have gradually weakened, having failed to recognize and maximize efforts of all parastatal primarily devoted to improving health (including organizations, institutions, structures, and resources) [1, 3].

Health workforce is an integral part of the health system and plays a critical role in achieving effective healthcare delivery. According to the World Health Organization (WHO), they are people "primarily engaged in action with the intent of enhancing health" diagnosing illnesses, healing, caring for people, monitoring health outcomes, supporting treatment adherence, providing medical information, and preventing diseases [4-5]. They consist of physicians, nurses, midwives, dentists, pharmacists, laboratory workers, environment \& public health workers, community health workers, other health workers, and health management, and support staff [6-7]. The correlation between the availability of health workforce and positive health outcomes has been observed by several studies [1, 8].

In 2007, there was an inadequate figure of 35 doctors and 86 nurses per 100,000 populations of Nigerians comparable to Sub-Saharan average of 15 doctors and 72 nurses per 100,000 population; a region that contributes to a quarter of the global burden of disease $[5,9]$. These figures have remained inadequate over the years; with Nigeria reporting a health workforce of 195 (doctors and nurses) per 100,000 ten years from the 2006 world health report [10]. This scenario has been linked to inadequate production and inequitable distribution across the country $[3,10-11]$. With massive historical brain drain which already has been documented to have caused setbacks in the country's health system [12] and declining recent brain drain still being experienced in Africa (including Nigeria); especially of doctors (25\%) [10] and nurses (5\%) [13], the number of Community Pharmacists are also grossly inadequate [14] and hence the need for other cadres of staff to fill in the gap and improve healthcare (especially basic public health services).

Although not always recognized as front-line health workers, across many countries in Sub-Saharan Africa (including Nigeria), medicine shops offer an alternative, when there are shortages in the health sector (including human resource shortage) and are usually the first point of care-seeking in most communities [15-18]. As reported by the National demographic health survey, nearly half (41\%) of contraceptives users in Nigeria obtain their contraceptives from the private sector, with more than half of all mothers/guardians seeking care from this sector for childhood illness such as Diarrhea (54.1\%) and Fever (57.7\%) [19]. Major reasons noted for this occurrence in several studies include the absence of formalities, reduced waiting time at the Medicine shop, the proximity of the outlets to clients, and the perception of clients that they will pay more at a health facility [20-21]. Patent and Proprietary Medicine Vendors (PPMVs) are increasingly being recognized as important providers of health commodities, as interest continues to grow among policymakers and Program implementers regarding their engagement in Primary Health Care delivery in Nigeria [16]. In some settings, training medicine vendors to provide high-quality basic services, such as family planning (FP) services, treatment of common childhood illnesses and malaria, may offer a cost-effective way of delivering community-based health programs [17, 20, 22]. The Pharmacists Council of Nigeria (PCN) undertakes the registration, regulation, and licensure of PPMVs, conducting orientation programs for new PPMVs, continuing education programs for existing PPMVs, inspection, and publishing the Approved Patent Medicine List (APML) [23]. Studies have however shown a reluctance of medicine vendors to register with the regulatory body and preferring to register with their trade associations, which also provide drug stocking support, facilitate education and training, and give business and financial assistance [18, 24-25]. 
In 2014, Nigeria issued the task-shifting and task-sharing (TSTS) policy for essential health services in Nigeria which aimed to fill the human resource gap and improve the delivery of health services across the country [26]. The policy highlighted the need to expand services to community-based personnel including Medicine vendors to provide treatment, counseling, and referral for some reproductive, maternal, and child health services (including FP) [26-27]. Previous studies have shown that different professionals may be operating within the PPMV space (even some with medical training $[17,28]$. Thus, the integration of this group of private providers into the formal healthcare system could increase access to high quality, primary health care services throughout the country [18].

In an initial study conducted in 2014, Liu and colleagues estimated the number of vendors in Nigeria and offered clues to drug stocking practices and how this group of healthcare workers could be better engaged to improve healthcare across the country [18]. However, it has been four years since the initial study and with the support recently showed to this group of health workers through the TSTS policy, there is the need to conduct further characterization and distribution of medicine vendors. This study focuses on the characteristics, spread, and FP stocking practices of PPMVs in Lagos and Kaduna states of Nigeria. It also assesses the influence of health training and other factors on the provision and stocking of FP services and commodities respectively by medicine vendors.

\section{Methodology}

Between February and September 2018, a census of all Medicine shops in Lagos and Kaduna states was conducted. The census collected information on the basic characteristics of the shop, educational qualification of the owner, and number/type of support staff working in the shops. Geographical coordinates of each shop were also recorded using the global positioning system (GPS) configured into the electronic tool used for data collection; adjusted to an accuracy of 5 meters. The states were purposively selected because of a planned FP intervention, regional differences between northern and southern Nigeria and comparability of findings with the Lui et al study conducted in 2014 (Lagos was one of the states chosen in that study and will show how things have changed whereas Kaduna will represent a new look and give insights about some states not represented in the 2014 study).

Data collectors worked with a list of PPMVs provided by the PCN, directorate of Pharmaceutical Services of Ministry of Health, and trade associations in the States. From the list, data collectors also snow-balled until all PPMVs in the LGAs were covered.

Following the census, a more robust facility assessment was conducted among a sample comprising about $10 \%$ of the mapped PPMV Shops; these shops were randomly selected from the 14 implementation LGAs systematically selected for the project in the two states (5 rural and 8 urban). The assessment aimed to elicit additional information not collected during the census. This assessment occurred between October and December 2018 and utilized an interviewer-administered questionnaire programmed using the Census and Survey Processing System (CSPro) into mobile phones through the CSentry Application.

A medicine vendor was regarded as having health (medical) training if he/she reported having qualification listed as Medical Doctor, Nurse, Midwife or Pharmacist or having completed a training program as a Community Health Extension Worker or a two/three-year clinical training program as a Junior Community Health Extension Worker [18]. 
Major outcomes in this study included (1) Current stock of FP products, including any brand of oral contraceptives, injectable contraceptives (and DMPA-SC), emergency contraception, intrauterine contraceptive device; (2) registration with a trade association or the PCN; (3) Source of Supply of FP commodity (defined as whether or not the vendor bought FP commodities from the Open Market). Major predictors in the study included health training of medicine vendor, training attendance (defined as PPMV shops in which at least one person has ever attended training on FP products and services), and Location of the PPMV shop (defined as Rural or Urban).

Other variables recorded in this study included the number of staff working in the facility, the estimated number of FP clients per day, and the length of time PPMV has been in business. The number of shops per 100,000 population in each local government area, using the 2006 national census estimates adjusted for population growth to 2017 was calculated. In addition, the percentage of vendors who had health training was calculated. Both parameters were shown graphically using maps culled from both states (showing LGAs).

Data were reported as frequencies and percentages to describe the various variables used in this study. Bivariate analysis was conducted using the chi-square test. Multiple logistic regression was used to estimate the adjusted odds ratio (OR) and confidence intervals (C.I) for the test of significance in the study. Statistical and spatial analyses were conducted using Stata v.14.0, and QGIS v.3.8, all tests were 2 sided and p-values $<0.05$ were considered as statistically significant.

Two models were employed for the logistic regression; Model 1 examined the association between Health Training of medicine vendor and Registration, Stocking and Source of FP products while controlling for State, Location (Urban/Rural), number of staff, number of FP clients and length of time business started. Model 2 examined the association between Length of time business started and Registration, Stocking and Source of FP products while controlling for State, Location, number of FP clients, and health training of the vendor.

\section{Results}

We visited a total of 8,318 PPMVs in the study; the majority of these were in the urban areas (76.2\%). Tables 1 and 2 shows the characteristics of shops identified across the 43 local governments areas (LGAs) in both states. The number of shops identified varied from 42 and 33 in Jaba and Ikeja LGAs of Kaduna and Lagos states respectively to 1045 and 999 identified in Chikun and Alimosho LGAs of both states. The results also show the number of medicine shops per 100,000 population in each of the LGAs. On average, there were 39 shops per 100,000 population in both states combined: 29 per 100,000 in the Rural and 48 per 100,000 in the urban areas. More specifically, Kaduna state showed a higher percentage on the average; 46 shops per 100,000 population compared to 32 per 100,000 observed in Lagos State (Maps shown in Fig. 2).

There were 2,345 shops (28.2\%) in which the medicine vendor (person in charge) had some form of health training. Figure 3 shows the proportion of PPMVs with health training in each of the LGAs across both states. The average percentage was significantly higher in the rural areas (32.2\%) and in Kaduna State (37.9\%) than urban areas (19.7\%) and Lagos State (11.3\%). About half (50.9\%) of the shops were solely manned by the medicine vendor without assistance, about one-third (31.9\%) had staff ranging from 1-3 persons and only a quarter of the shops had more than four (4) staff. 
Table 1

Census of Patent and Proprietary medicine shops in Kaduna and Lagos States, 2018

\begin{tabular}{|ll|}
\hline Characteristics & $\begin{array}{l}\text { Number of Shops (\%) } \\
(\mathbf{N}=8,318)\end{array}$ \\
\hline State & $4572(55.0)$ \\
\hline Kaduna & $3746(45.0)$ \\
\hline Lagos & \\
\hline Location & $6339(76.2)$ \\
\hline Urban & $1979(23.8)$ \\
\hline Rural & \\
\hline Health training of medicine vendor & $5973(71.8)$ \\
\hline No Health Training & $1201(14.4)$ \\
\hline Community Health Extension Worker or Community Health Officer & $797(9.6)$ \\
\hline Nurse or Midwife & $133(1.6)$ \\
\hline Junior Community health extension worker & $5(0.1)$ \\
\hline Doctor & $209(2.5)$ \\
\hline Other health-care workers & $2618(31.9)$ \\
\hline Number of Support Staff* & $1410(17.2)$ \\
\hline 0 & $4180(50.9)$ \\
\hline $1-3$ & \\
\hline$\geq 4$ & \\
\hline * Data were available for only 8,208 shop & \\
\hline
\end{tabular}


Table 2

Summary of LGA Census of PPMVs in Kaduna and Lagos States, 2018

\begin{tabular}{|c|c|c|c|c|c|c|c|}
\hline LGA & Freq & $\begin{array}{l}\text { PPMV/100,000 } \\
\text { Population }\end{array}$ & $\begin{array}{l}\text { Proportion } \\
\text { of PPMVs } \\
\text { with } \\
\text { Health } \\
\text { Training }\end{array}$ & LGA & Freq & $\begin{array}{l}\text { PPMV/100,000 } \\
\text { Population }\end{array}$ & $\begin{array}{l}\text { Proportion } \\
\text { of PPMVs } \\
\text { with } \\
\text { Health } \\
\text { Training }\end{array}$ \\
\hline \multicolumn{4}{|c|}{ Kaduna State } & \multicolumn{4}{|l|}{ Lagos State } \\
\hline $\begin{array}{l}\text { Birnin } \\
\text { Gwari }\end{array}$ & 69 & 20 & 13.0 & Ajeromi/Ifelodun & 112 & 12 & 4.5 \\
\hline Chikun & 1045 & 205 & 47.1 & Alimosho & 999 & 55 & 8.9 \\
\hline Giwa & 108 & 27 & 31.5 & Amuwo Odofin & 179 & 40 & 14.5 \\
\hline Igabi & 666 & 112 & 46.2 & Apapa & 131 & 43 & 2.3 \\
\hline Ikara & 67 & 25 & 22.4 & Badagry & 330 & 97 & 8.8 \\
\hline Jaba & 42 & 20 & 33.3 & Epe & 73 & 28 & 9.6 \\
\hline Jema'a & 178 & 46 & 50.6 & Eti Osa & 53 & 13 & 11.3 \\
\hline Kachia & 91 & 27 & 30.8 & Ibeju Lekki & 148 & 89 & 19.6 \\
\hline $\begin{array}{l}\text { Kaduna } \\
\text { North }\end{array}$ & 516 & 104 & 31.2 & Ifako/ljaye & 317 & 52 & 17.0 \\
\hline $\begin{array}{l}\text { kaduna } \\
\text { South }\end{array}$ & 558 & 100 & 47.0 & Ikeja & 33 & 7 & 27.3 \\
\hline Kagarko & 48 & 14 & 12.5 & Ikorodu & 327 & 43 & 16.2 \\
\hline Kauru & 57 & 37 & 45.6 & Kosofe & 49 & 5 & 16.3 \\
\hline Kaura & 47 & 15 & 57.4 & Lagos Island & 71 & 24 & 4.2 \\
\hline Kauru & 65 & 28 & 52.3 & Lagos Mainland & 68 & 15 & 11.8 \\
\hline Kuban & 45 & 12 & 11.1 & Mushin & 105 & 12 & 6.7 \\
\hline Kudan & 66 & 34 & 48.5 & Ojo & 297 & 35 & 14.8 \\
\hline Lere & 126 & 27 & 31.7 & Oshodi/Isolo & 151 & 17 & 6.0 \\
\hline Makarfi & 50 & 25 & 42.0 & Shomolu & 100 & 18 & 8.0 \\
\hline $\begin{array}{l}\text { Sabon } \\
\text { Gari }\end{array}$ & 272 & 68 & 41.2 & Surulere & 80 & 11 & 8.8 \\
\hline Sanga & 57 & 28 & 33.3 & Agege & 123 & 19 & 8.9 \\
\hline Soba & 89 & 22 & 50.6 & Total & 3746 & 32 & 11.3 \\
\hline $\begin{array}{l}\text { Zangon } \\
\text { Kataf }\end{array}$ & 44 & 10 & 43.2 & & & & \\
\hline Zaria & 266 & 47 & 49.2 & & & & \\
\hline Total & 4572 & 46 & 37.9 & & & & \\
\hline
\end{tabular}


The assessment data also showed similar patterns with the census; with Kaduna (65.2\%) and urban areas (84.4\%) contributing largely to the sample. Table 3 shows additional characteristics of shops visited; we observed that eight (81.6\%) of every 10 medicine shops across these two states are open daily; only 8 shops reported opening for less than six days per week. The results also showed that $47 \%$ of the shops are relatively new businesses; opening within the last 5 years; about ten percent (8.2\%) opening within the same year as the study (2018). Registration status showed that more than half $(56.1 \%)$ of all vendors were registered with the PCN, others registered with a national or local medicine dealers' association; about one in every ten vendors $(11.4 \%)$ were not registered with any association or regulatory body. Vendors operating in Lagos (Southern Nigeria) reported higher registration rates than their counterparts in Kaduna (Northern Nigeria); $83.2 \%$ compared to $41.6 \%$.

On Family planning (FP) services/products being stocked by the medicine shops, about a quarter (25.7\%) of vendors claimed to provide FP services to > 2 clients per week on the average; about the same number $(26.9 \%)$ have had at least one person in the shop attend training on FP in the past. The majority (86.8\%) of shops stocked at least one of the oral contraceptives, about half stocked Injectable contraceptives (45.5\%), and Emergency contraceptives (46.5\%). Only 18 shops stocked Intrauterine devices or Implant contraceptives. We also found that the majority (76.0\%) of providers reported the open market as the major source of stocking these FP commodities; this however showed marked state differences. In Kaduna state, the open market accounted for the main source of supply of FP commodities, serving $95 \%$ of providers compared to less than half $(42.1 \%)$ of shops in Lagos state. 
Table 3

Facility Assessment of Patent and Proprietary Medicine Shops in Kaduna and Lagos, 2018

\section{Characteristics}

Number (\%)

of Shops

$(\mathrm{N}=874)$

\section{State}

Kaduna

$570(65.2)$

Lagos

$304(34.8)$

\section{Location}

Urban

738 (84.4)

Rural

304 (15.6)

Number of days shop opens per week ${ }^{a}$

$\leq 5$ days

$8(1.0)$

6 days

140 (17.4)

7 days

657 (81.6)

Length of time business started ${ }^{b}$

$<1$ year

$71(8.2)$

$1-5$ years

$337(38.8)$

6-10 years

$183(21.1)$

$>10$ years

$277(31.9)$

\section{Registration}

Not Registered with any association/regulatory body

National or Local Association of Medicine Vendors

Pharmacist Council of Nigeria

Number of Client for Family Planning per day

0

$232(28.5)$

1

373 (45.8)

$117(14.4)$

2

92 (11.3)

$\geq 3$

(11.3)

Ever Attended Training on Family Planning ${ }^{c}$

Yes

219 (26.9)

FP Product Stocking Practice ${ }^{d}$ 


\begin{tabular}{|l|l|}
\hline Characteristics & $\begin{array}{l}\text { Number (\%) } \\
\text { of Shops } \\
\mathbf{( N = 8 7 4 )}\end{array}$ \\
\hline Any Oral Contraceptive & $652(86.8)$ \\
\hline Injectable Contraceptive & $342(45.5)$ \\
\hline Emergency Contraception & $349(46.5)$ \\
\hline Intrauterine Contraceptive Device & $10(1.3)$ \\
\hline Implant Contraceptive & $8(1.1)$ \\
\hline Open Market as Major source of FP Products ${ }^{c}$ & $619(76.0)$ \\
\hline $\begin{array}{l}\text { a Data Available for only 805 shops; b Data Available for only 868 shops; c Data Available for } \\
\text { only 814 shopsd Data Available for only 751 shops }\end{array}$ \\
\hline
\end{tabular}

The bivariate analysis (shown in Table 4) found a significant association between health training and all outcomes observed (product stocking of FP commodities, Registration status, and Supply from open drug market). Significant associations were also found between the length of time the PPMV business started and outcomes (except stocking of oral and emergency contraceptives). We also found a significant association between length of time business opened and health training of vendor; findings show that a significantly larger number $(56.3 \%)$ of newly opened PPMV shops are manned by those who reported to have health training; those newly opened shops are 1.8 times more likely to be health trained compared to those opened $>5$ years before the study. After controlling for confounders in the multivariate analysis (shown in Table 5), many of the associations remained significant (especially those relating to health training of vendors). Consequently, there was a significant association between health training and the likelihood of vendor stocking oral and injectable contraceptives. Also, there is a significantly reduced likelihood of health trained vendors stocking from the open market compared to those not health trained. Although there was an observed increased likelihood of newly opened PPMV shops to utilize the open market as the major means of stocking products; this relationship was not shown to be significant after adjusting for confounders.

Health training of the vendor did not prove to be a significant predictor of registration status although some differences exist. Those who are health trained seem to be more likely to register with the PCN than with national/local medicine dealers' associations compared to those not health trained. The same can be said for those who reported opening within 5 years of the study compared to PPMV shops which have operated for longer periods. 
Table 4

Bivariate Analysis showing the association between Health Training/Newly PPMV Outlets and Product Stocking, Registration and Source of FP Products

\begin{tabular}{|c|c|c|c|c|c|c|}
\hline \multirow[t]{2}{*}{ Outcome } & \multicolumn{3}{|c|}{$\begin{array}{l}\text { NO. (\%) of Medicine Vendors with } \\
\text { any health training }\end{array}$} & \multicolumn{3}{|c|}{$\begin{array}{l}\text { No. (\%) of Length of time PPMV } \\
\text { Business Started }\end{array}$} \\
\hline & Yes & No & Sig. & $0-5$ Years & $>5$ Years & Sig. \\
\hline \multicolumn{7}{|l|}{ Product Stocking } \\
\hline Any Oral Contraceptive & 85.3 & 76.8 & * & 80.1 & 80.1 & \\
\hline Injectable Contraceptive & 65.2 & 27.1 & ** & 48.9 & 35.8 & ** \\
\hline Emergency Contraception & 48.9 & 39.0 & * & 42.3 & 43.4 & \\
\hline \multicolumn{7}{|l|}{ Registration } \\
\hline $\begin{array}{l}\text { National or Local Association of } \\
\text { Medicine Vendors }\end{array}$ & 44.9 & 31.6 & ** & 41.0 & 33.0 & * \\
\hline Pharmacists Council of Nigeria & 55.1 & 68.4 & ** & 59.1 & 67.1 & * \\
\hline \multicolumn{7}{|l|}{ Source of FP Products } \\
\hline Open Market & 71.3 & 83.4 & ** & 83.8 & 69.1 & $\star \star$ \\
\hline Open Market (Kaduna) & 94.8 & 95.3 & & 95.9 & 93.8 & \\
\hline Open Market (Lagos) & 22.0 & 46.3 & * & 41.7 & 42.3 & \\
\hline Health Training of Vendor & & & & 56.3 & 43.7 & $\star *$ \\
\hline
\end{tabular}


Table 5

Multivariate Analysis showing the association between Health Training/Newly PPMV Outlets and Product Stocking, Registration and Source of FP Products

\begin{tabular}{|c|c|c|c|c|}
\hline \multirow[t]{3}{*}{ Outcome } & \multirow{2}{*}{\multicolumn{2}{|c|}{$\begin{array}{l}\text { Model } 1 \text { (Health Training of } \\
\text { Vendor) } \\
\text { OR }(95 \% \mathrm{Cl})^{a}\end{array}$}} & \multirow{2}{*}{\multicolumn{2}{|c|}{$\begin{array}{l}\text { Model } 2 \text { (PPMVs Opened in } \leq 5 \\
\text { Years) } \\
\text { OR }(95 \% \mathrm{Cl})^{b}\end{array}$}} \\
\hline & & & & \\
\hline & Crude & Adjusted & Crude & Adjusted \\
\hline \multicolumn{5}{|l|}{ Product Stocking } \\
\hline Any Oral Contraceptive & $\begin{array}{l}1.75(1.21- \\
2.54)\end{array}$ & $\begin{array}{l}2.20(1.47- \\
3.30)\end{array}$ & & \\
\hline Injectable Contraceptive & $\begin{array}{l}5.05(3.73- \\
6.84)\end{array}$ & $\begin{array}{l}3.15(2.17- \\
4.58)\end{array}$ & $\begin{array}{l}1.72(1.30- \\
2.28)\end{array}$ & $\begin{array}{l}0.73(0.50- \\
1.06)\end{array}$ \\
\hline Emergency Contraception & $\begin{array}{l}1.50(1.13- \\
1.99)\end{array}$ & $\begin{array}{l}1.26(0.92- \\
1.74)\end{array}$ & & \\
\hline \multicolumn{5}{|l|}{ Registration } \\
\hline $\begin{array}{l}\text { National or Local Association of } \\
\text { Medicine Vendors }\end{array}$ & $\begin{array}{l}1.77(1.31- \\
2.38)\end{array}$ & $\begin{array}{l}0.93(0.65- \\
1.33)\end{array}$ & $\begin{array}{l}1.41(1.05- \\
1.90)\end{array}$ & $\begin{array}{l}0.88(0.62- \\
1.25)\end{array}$ \\
\hline Pharmacist Council of Nigeria & $\begin{array}{l}0.57(0.42- \\
0.76)\end{array}$ & $\begin{array}{l}1.08(0.75- \\
1.55)\end{array}$ & $\begin{array}{l}0.71(0.53- \\
0.95)\end{array}$ & $\begin{array}{l}1.14(0.80- \\
1.61)\end{array}$ \\
\hline \multicolumn{5}{|l|}{ Source of FP Products } \\
\hline Open Market ${ }^{\star}$ adj for state & $\begin{array}{l}0.50(0.30- \\
0.84)\end{array}$ & $\begin{array}{l}0.51(0.30- \\
0.87)\end{array}$ & $\begin{array}{l}1.12(0.73- \\
1.72)\end{array}$ & $\begin{array}{l}1.19(0.77- \\
1.85)\end{array}$ \\
\hline Health Training of Vendor & & & $\begin{array}{l}1.84(1.39- \\
2.42)\end{array}$ & $\begin{array}{l}1.42(1.04- \\
1.94)\end{array}$ \\
\hline \multicolumn{5}{|c|}{$\begin{array}{l}\text { a Odds Ratio (OR) with Confidence Intervals estimated using logistic regression. Reference Category is vendors } \\
\text { without Health Training; b Odds Ratio (OR) with Confidence Intervals estimated using logistic regression. } \\
\text { Reference Category is vendors who started operating more than } 5 \text { years before the study. Model } 1 \text { examines the } \\
\text { association between Health Training of vendor and Registration, Stocking and Source of FP products while } \\
\text { controlling for State, Location (Urban/Rural), number of staff, number of FP clients, and length of time } \\
\text { business started. Model } 2 \text { examines the association between Length of time business started and Registration, } \\
\text { Stocking and Source of FP products while controlling for State, Location (Urban/Rural), number of staff, } \\
\text { number of FP clients, and health training of vendor. }\end{array}$} \\
\hline
\end{tabular}

\section{Discussion}

The findings from this study, like the Liu et al study among others, revealed that PPMV shops were numerous in the two states. With fewer health facilities and health posts opening across the country [29] and fewer pharmacies opening up (especially in rural and hard to reach areas) [14], PPMVs have remained the most widespread health structure across the two (2) states; and across Northern and Southern Nigeria [18]. However, the study found a greater concentration of shops in the Northern state of Kaduna and especially in the urban areas; this is a slight deviation from the norm in many studies that PPMVs are mainly located in the rural and hard to reach areas [16, $22,30]$. 
As Nigeria strives to achieve Universal Health Coverage (UHC) and improve access to quality health services, the role of PPMVs has become more important. One of the domains of access listed in the UHC includes physical access to health services; this physical accessibility is dependent on the proximity of health facilities to potential clients [31]. In a recent study where the distribution of health facilities across Nigeria was documented, primary health facilities, more than other facilities were most prominent across the country (ranging 15.5 and 18.4 per 100,000 population in Southern and Northern states respectively) [29]. The findings from our study showed that the distribution of PPMV shops in these regions more than doubled that of the most populous health facilities; ranking 32 and 46 per 100,000 respectively in Southern state of Lagos and Northern state of Kaduna; this corroborates the findings of Liu and colleagues that PPMVs may be more accessible than health care facilities in many places across Nigeria. The figures in this study revealed a considerable increase from the figures shown in 2014 where there were 32 versus 24 per 100,000 in the Southern states and a similar 17 per 100,000 in the Northern States between PPMV shops and health care facilities [18]. The findings remained the same even when state comparison was done between this study and the study by Makinde and colleagues. In addition, the study found that PPMV shops have continued to grow progressively in the last five (5) years; further increasing the margins between the numbers of PPMV shops and health care facilities and thus, becoming the most proximal health facility for potential clients for different health care services.

Also, there is an emergence of PPMVs reporting formal health training. These findings have also been observed by a few studies in the past $[15,18,28]$ and are still relevant today. This suggests a deviation from the general definition of medicine vendors, who are characterized as being able to read and write [23], having completed mainly primary education and not having formal training in medicine and pharmacy [32-33]. Many of them were also thought to learn the trade through an apprenticeship program before opening their shops [16]. Our findings show that more than half of the vendors who reported health training are relatively new in the business, opening within the last five (5) years. This suggests the rise of vendors who may be able to deliver high-quality health services and complement the existing healthcare infrastructure [17] due to their formal training and previous experience (some being retired providers who worked at public/private health facilities across the country). The findings from this study show a significant relationship between health training of vendors and stocking of some FP commodities (especially Injectable contraceptives) with clients that patronize them for FP services every month (this supports findings elsewhere in Nigeria and Africa that PPMVs already offer injectable contraception) and other services [27, 34]. This supports the evidence that PPMVs can support the formal health systems as these are services that they can provide, because of their training and the recent task-shifting and task-sharing policy of the country. Unfortunately, some services being provided are currently prohibited within the scope of PPMVs [17, 26, 30,32 ]. As many other studies have suggested, this study found that concerns may exist in the delivery of quality services by PPMVs as many of those interviewed stocked illegal commodities (beyond their legal scope of practice) and refused to register with the pharmacy practice regulatory body (PCN) $[16,18,30]$. Despite the findings, studies have suggested that demand (especially women and adolescents) could be driving the stocking and sale of those categories of drugs especially when the drugs are not available in the formal health facilities [30, 35]. This, in addition to the geographic spread of the medicine vendors, has implications for the healthcare system in Nigeria and necessitates the expansion for more services (including FP) to PPMVs beyond their current scope of practice especially for those reporting formal health training, as have been demonstrated in many pilot studies across Africa (including Nigeria) [22,36-40]. This will be in line with the TSTS policy of the country which calls for an increase in the capacity of community people to provide some reproductive, maternal, and child health services [18]. Strengthening the collaboration between this informal sector and the formal health sector may go a long way in improving the confidence of medicine vendors to legitimately stock drugs that they are capable of providing

Page $13 / 20$ 
according to their qualification and improving referral for higher levels of care sought by the vast population that patronize them.

The findings of the study also show that health training of a PPMV and age of business existence may influence registration status with the PCN, although this was not found to be significant after adjusting for the state, location, and the number of FP clients. There is a possibility that newly opened shops with health trained vendors are more likely than others to register with the PCN, suggesting a possible improvement in the relationship between PCN and the association of patent medicine vendors in the last 3 years. This finding shows that health trained vendors may more likely adhere to regulatory and quality assurance guidelines; thus, corroborating the findings found by other investigators $[18,30]$. This also suggests that newly opened vendors may be willing to register with the PCN at the start, but the influence of older PPMVs and the majority of who are without health training may further drag new PPMVs into not desiring to register annually with the regulator but rather with the trade associations, or not registering at all, hence operating illegally. As noted by several studies, the trade associations are perceived to be more beneficial to the vendors than PCN for several reasons, ranging from providing them with protection against law enforcement agents to oversight functions (especially with preventing illegal drug sellers and monitoring of the sale of drugs) to members through a taskforce and peer- to- peer mentoring; these are generally more acceptable by the medicine vendors [24,30]. There is thus a need for a collaborative framework between the associations and PCN to improve registration of PPMVs and their perception about the roles of PCN against the current antagonistic standpoint. PCN needs to be seen to perform more supportive roles to foster trust and respect; which could lead to a suitable accreditation system, an opportunity for professionals to expand their scope through continuous learning, and ultimately have the drug list expanded to fit the realities of the sector. This may result in more health trained vendors joining the business and offering a great opportunity to further improve the quality of health services provided to the populace, leading to better health outcomes.

Lastly, our findings support the claim of many studies that many vendors utilize the open market as the major source of supplying health products [17-18, 41-42]. Even though the National Drug Distribution Guideline has as part of its core deliverables, the elimination of the dominance of unregulated drug markets in major cities of Nigeria [43-44], however, the findings from our study show that these markets still supply the majority of the vendors (especially in the northern part of the country). In the southern part of the country, reliance on open markets is common among those without health qualifications and in the rural areas (where mega dealers/wholesalers are few). Drug distribution requires efficient supply chain systems and appropriate regulation to ensure that the medicines that reach the consumer are in their intended qualitative state, supported with the required infrastructure to ensure rational use; this, however, is not the case across both states as vendors still source for drugs in these markets where drugs are peddled without caution. For the most part, only the public and few private health facilities are catered for by the national drug distribution centers (MDDC and SDDC) [45].

This study has several limitations; chiefly, by combining the results of two studies conducted at different times, there is a possibility of missing some key characteristics from PPMV shops not included in both studies, especially as the second study (facility assessment) focused on PPMVs in proposed implementation LGAs. Also, recall bias is a possibility with this study type, as some of the variables self-reported by PPMVs could not be verified in both studies, only GPS coordinates, licensing status with the PCN, and product stocking could be independently verified.

\section{Conclusion}


PPMVs have continued to grow progressively in the last five years, becoming the most proximal health facility for potential clients for different health care services (especially FP services) across both northern and southern Nigeria. they are now comprised of a considerable mass of health trained personnel, able to deliver high-quality health services and complement existing health care infrastructure if trained. However, restrictions on what is possible within the PPMV shop and lack of access to quality health commodities have resulted in some poor practices among PPMVs. There is therefore a need to identify, train, and provide innovative means of improving access to quality-assured products for this group of health workers. This may significantly reduce the stocking of inadequate or substandard medicines, reduce the stock-out of key health commodities, and further improve the quality of services provided by these providers and ultimately, the health outcome of the populace.

\section{Abbreviations}

APML

Approved Patent Medicine List

$\mathrm{Cl}$

Confidence Interval

CSPro

Census and Survey Processing System

DMPA-Sc

Subcutaneous DepoMedroxyProgesterone Acetate

FP

Family Planning

GPS

Global Positioning System

LGA

Local Government Areas

LMICs

Low- and Middle-Income Countries

MDDC

Mega Drug Distribution Centre

OR

Odds Ratio

PCN

Pharmacists Council of Nigeria

PPMVs

Patent and Proprietary Medicine Vendors

SDDC

State Drug Distribution Centre

TSTS

Task-shifting and Task-sharing

UHC

Universal Health Coverage

WHO

World Health Organization 


\section{Declarations}

\section{Ethics approval and consent to participate}

Not Applicable. The unit of study was medicine shops.

Consent to publish

Not Applicable.

Availability of data and materials

The datasets used and/or analyzed during the current study are available from the corresponding author on reasonable request.

\section{Competing Interests}

The authors declare that they do not have any competing interests. The funders of this study did not have any role in the design, planning, or execution of this work.

\section{Funding}

The authors are grateful for funding support provided by the IntegratE project consortium, funded by the Bill and Melinda Gates Foundation and Merck Sharpe and Dohme for Mothers (MSDfM), led by the Society for Family Health. The opinions and inferences made in this work are those of the authors and not the funding agencies.

Authors' Contributions

$\mathrm{BD}$ and $\mathrm{JA}$ conceived the overall study. $\mathrm{BD}$ and $\mathrm{SB}$ conducted the analysis. $\mathrm{BD}$ wrote the manuscript with assistance and contributions from EO, SB, and JA. OA and EO also provided technical assistance in the execution of the mapping/data collection. All authors read and approved the final manuscript.

\section{Acknowledgments}

The authors are grateful to Bolaji Oladejo and Murtala Muhammad Ibrahim, Program Managers in the two states of IntegratE Project implementation, for their guidance during the fieldwork and data collection. We also appreciate other members of the IntegratE team in Lagos and Kaduna for their excellent work during the fieldwork and providing feedback on manuscript preparation. We would also like to acknowledge the work of Louwese Hycienth in helping to generate the maps used for this work.

\section{References}

1. Singh P, Sachs JD. 1 million community health workers in sub-Saharan Africa by 2015. Lancet. 2013;382(9889):363-5.

2. World Health Organization. Everybody's business: strengthening health systems to improve health outcomes: WHO's framework for action. Geneva: World Health Organization; 2007

3. Adeloye D, David RA, Olaogun AA, Adesokan AA, Gadanya M, Opele JK, Owagbemi O, Iseolorunkanmi A. Health workforce and governance: the crisis in Nigeria. Human Resources for Health (2017) 15:32. DOI 
10.1186/s12960-017-0205-4

4. Adebayo O, Labiran A, Emerenini CF, Omoruyi L. Health Workforce for 2016-2030: Will Nigeria have enough? International Journal of Innovative Healthcare Research, 2016; 4(1):9-16.

5. World Health Organization. The World Health Report 2006-working together for health. Geneva: World Health Organization; 2006.

6. Diallo K, Zurn P, Gupta N, Dal Poz M. Monitoring and evaluation of human resources for health: an international perspective. Human resources for health. 2003 Apr 14;1(1):3.

7. International Labour Office (ILO). International standard classification of occupations: ISCO-88. 1990

8. Nguyen PM, Mirzoev T, Le TM. Contribution of health workforce to health outcomes: empirical evidence from Vietnam; Human Resources for Health.2016; vol 14, Article number: 68

9. Labiran A, Mafe M, Onajole B, and Lambo E. "Health Workforce country profile for Nigeria." Africa Health Workforce Observatory 8 (2008).

10. World Health Organization. Nigeria: Global Health Workforce Alliance. Geneva: World Health Organization; 2016.

11. Abimbola S, Olanipekun T, Schaaf M, Negin J, Jan S, Martiniuk AL. Where there is no policy: governing the posting and transfer of primary health care workers in Nigeria. Int J Health Plann Manage 2016. Oct;32(4):492508.

12. Ike SO. The health workforce crisis: the brain drain scourge. Niger J Med. 2007; 16:204-11.

13. World Health Organization. Health systems. In: World Health Statistics 2014. Geneva: World Health Organization; 2014. p. 128-40.

14. Ekpenyong A, Udoh A, Kpokiri E, Bates I. An analysis of pharmacy workforce capacity in Nigeria. Journal of Pharmaceutical Policy and Practice. 2018;11-20. https://doi.org/10.1186/s40545-018-0147-9

15. Prach LM, Treleaven E, Isiguzo C, Liu J. Care seeking at patent and proprietary medicine vendors in Nigeria Health systems and services in low- and middle-income settings. BMC Health Serv Res 2015; doi: 10.1186/s12913-015-0895-z.

16. Beyeler N, Liu J, Sieverding M. A systematic review of the role of proprietary and patent medicine vendors in healthcare provision in Nigeria. PLoS One, 2015; 10(1): e0117165.

17. Liu J, Beyeler N, Prach, LM, Sieverding M, Isiguzo C, Nwokolo E, Anyanti, J. The Landscape of Patent and Proprietary Medicine Vendors in 16 States of Nigeria. Abuja, Nigeria: Society for Family Health, 2015.

18. Liu J, Prach LM, Treleaven E, Hansen M, Anyanti J, Jagha T, Seaman V, Ajumobi O, Isiguzo C. The role of drug vendors in improving basic health-care services in Nigeria. Bulletin of the World Health Organization 2016; 94:267-275. doi: http://dx.doi.org/10.2471/BLT.15.154666

19. Nigeria Demographic and Health Survey (NDHS). National Population Commission; Federal Republic of Nigeria, 2018.

20. Daini BO, Anibi AU, Akin-Kolapo B, Fajemisin OA. Joint Effect/Interaction of Detailing and Trainings on Coverage of Family Planning Products Among Selected PPMV Shops in Nigeria. International Journal of Public Health Research 2018; 6(2): 26-34

21. Ankomah A, Ujuju C, Adebayo S, Anyanti J, Oluigbo O, Muhammad F. An assessment of the quality of advice provided by patent medicine vendors to users of oral contraceptive pills in urban Nigeria. J. Multidiscip. Healthc., 2014; 7: 163-171. 
22. Akol A, Chin-Quee D, Wamala-Mucheri P, Namwebya JH, Mercer SJ, Stanback J. Getting closer to people: family planning provision by drug shops in Uganda. Glob. Heal. Sci. Pract., 2014;2(4):472-81

23. Pharmacist Council of Nigeria (PCN) Guideline for the Issuance of Patent and Proprietary medicine vendor license; $2^{\text {nd }}$ edition, $3^{\text {rd }} 2014$.

24. Sieverding M, Liu J, Beyeler N. Social support in the practices of informal providers: the case of patent and proprietary medicine vendors in Nigeria. Soc Sci Med. 2015 Oct; 143:17-25

25. Oladepo O, Salami KK, Adeoye BW, Oshiname F, Ofi B, Oladepo M, et al. WP1 - Malaria treatment and policy in three regions in Nigeria: the role of patent medicine vendors [Internet]. Baltimore: Future Health Systems; 2007.

26. Task-shifting and task-sharing policy for essential health care services in Nigeria. Abuja: Nigeria Federal Ministry of Health; 2014.

27. Ishaku S, Afolabi K, Dwyer SC, Okunade F, Uzomba C, Adebayo A, Tobey E Jain A. Examining and Strengthening the Role of Patent and Proprietary Medicine Vendors in the Provision of Injectable Contraception in Nigeria. Research Report for Evidence Project. Found at http://evidenceproject.popcouncil.org/wp-content/uploads/2018/11/Examining-and-Strengthening-the-Rolesof-PPMVs-in-Nigeria_October-2018.pdf

28. Treleaven E, Liu J, Prach LM, Isiguzo C. Management of paediatric illnesses by patent and proprietary medicine vendors in Nigeria. Malar J. 2015;14(1):232.

29. Makinde OA, Sule A, Ayankogbe O, Boone D. Distribution of health facilities in Nigeria: Implications and options for Universal Health Coverage. Int J Health Plann Manage. 2018 Oct;33(4): e1179-e1192. doi: 10.1002/hpm.2603.

30. Durowade KA, Bolarinwa OA, Fenenga CJ, Akande TM. Operations and Roles of Patent and Proprietary Medicine Vendors in Selected Rural Communities in Edu Local Government Area, Kwara State, North-Central Nigeria. Journal of Community Medicine and Primary Health Care, 2018; 30(2) 75-89

31. Evans DB, Hsu J, Boerma T. Universal health coverage and universal access. Bull World Health Organ. 2013; 91:546-546A.

32. Brieger WR, Osamor PE, Salami KK, Oladepo O, Otusanya SA. Interactions between patent medicine vendors and customers in urban and rural Nigeria. Health Policy and Planning. 2004; May;19(3):177-82.

33. Egboh A. Pharmacy Laws and Practice in Nigeria, vol. PMID: 25057. 1984.

34. Corroon M, Kebede E, Spektor G, Speizer Key Role of Drug Shops and Pharmacies for Family Planning in Urban Nigeria and Kenya. Glob Health Sci Pract. 2016 Dec 23; 4(4): 594-609.

35. Okonkwo AD, Okonkwo UP. Patent medicine vendors, community pharmacists and STI management in Abuja, Nigeria. Afr. Health Sci., 2010; 10(3):253-65.

36. Keesbury J, Morgan G, Owino B. Is repeat use of emergency contraception common among pharmacy clients? Evidence from Kenya. Contraception. 2011;83(4):346-351. 10.1016/j.contraception.2010.08.010.

37. Kalyango JN, Alfven T, Peterson S, Mugenyi K, Karamagi C, Rutebemberwa E. Integrated community case management of malaria and pneumonia increases prompt and appropriate treatment for pneumonia symptoms in children under five years in Eastern Uganda. Malar J. 2013;12(1):340. http://dx.doi.org/10.1186/1475-2875-12-340 pmid: 24053172

38. Isiguzo C, Anyanti J, Ujuju C, Nwokolo E, De La Cruz A, Schatzkin E, et al. Presumptive treatment of malaria from formal and informal drug vendors in Nigeria. PLoS ONE. 2014;9(10): e110361. http://dx.doi.org/10.1371/journal.pone.0110361 pmid: 25333909 
39. Awor P, Wamani H, Tylleskar T, Jagoe G, Peterson S. Increased access to care and appropriateness of treatment at private sector drug shops with integrated management of malaria, pneumonia and diarrhoea: a quasi-experimental study in Uganda. PLoS ONE. 2014;9(12): e115440.

40. Stanback J, Lebetkin E, Orr T, Malarcher S. Family Planning Provision in Drug Shops Technical Consultation Participants. Sale and provision of injectable contraceptives in drug shops in developing countries: conclusions from a technical consultation. Contraception. 2015;91(2):93-96.

10.1016/j.contraception.2014.11.007

41. Health Communication Capacity Collaborative (HC3). Landscape of Antimalarial medicines in Nigeria., 2016. Project report downloaded from https://sbccimplementationkits.org/quality-malaria-medicines/wpcontent/uploads/sites/15/2016/10/Landscape-of-Antimalarial-Medicines-in-Nigeria.pdf

42. Palafox B, Patouillard E, Tougher S, Goodman C, Hanson K, Kleinschmidt I, Rueda ST, Kiefer S, O’Connell KA, Zinsou C, et al. Understanding Private Sector Antimalarial Distribution Chains: A Cross-Sectional Mixed Methods Study in Six Malaria-Endemic Countries. PLoS One. 2014; doi: 1371/journal.pone.0093763.

43. Ojo L. National drug distribution guidelines and benefits. 2017 (Internet).

https://guardian.ng/features/health/national-drug-distribution-guidelines-and-benefits/ (Cited 31st October 2019).

44. National Guidelines on Drug Distribution in Nigeria. Federal Ministry of Health (FMOH), Ed., 2012; 2: 1-31.

45. Onyebuchi OB. National Drug Distribution in Nigeria; Implications for the goals of National Drug Policy. European Journal of Pharmaceutical and Medical Research, 2016,3(1), 01-04

\section{Figures}

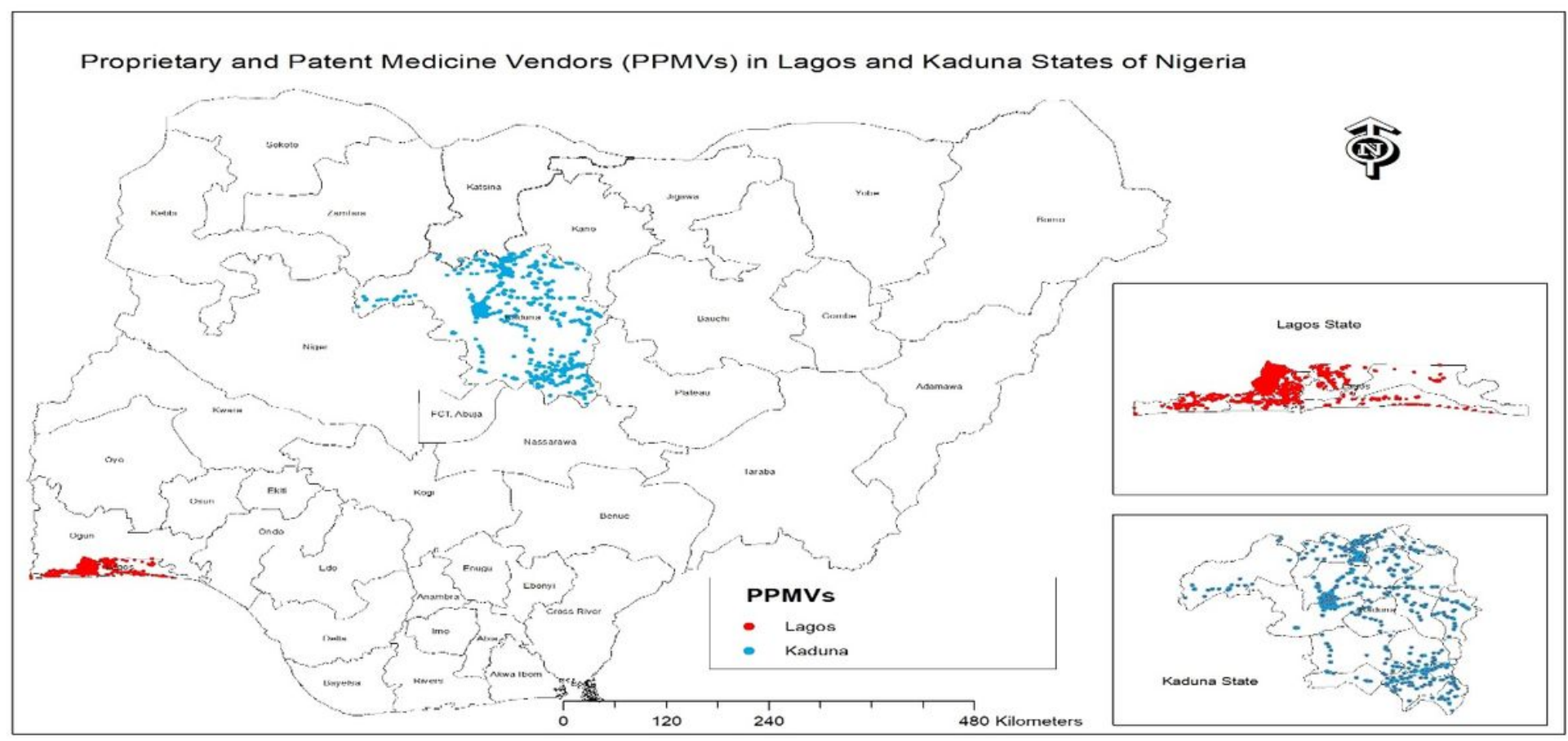

Figure 1

Location OF PPMVs Shops in 2 States 


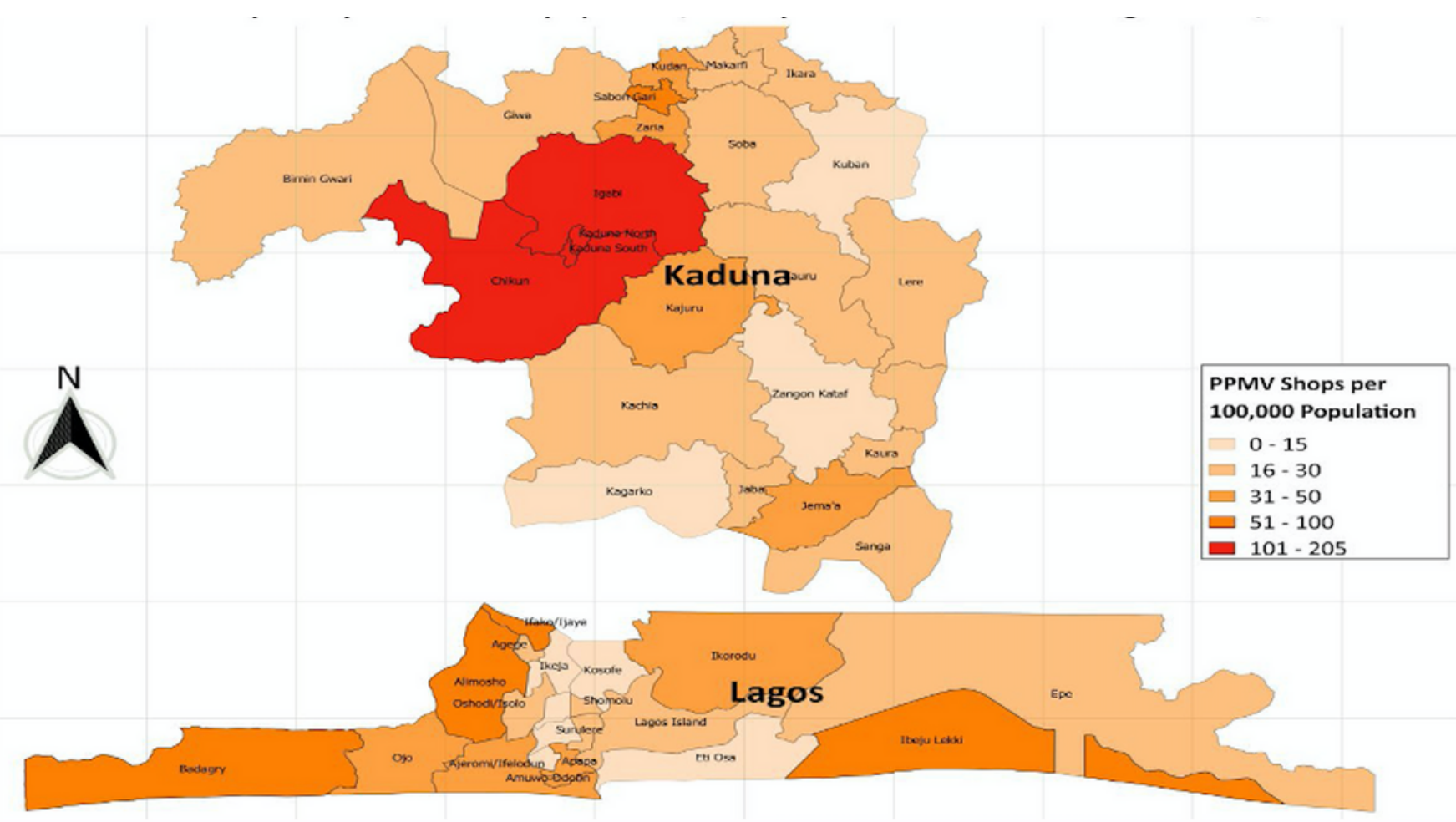

Figure 2

Patent and Proprietary Medicine Shops per 100,000 Population in Kaduna and Lagos States, 2018

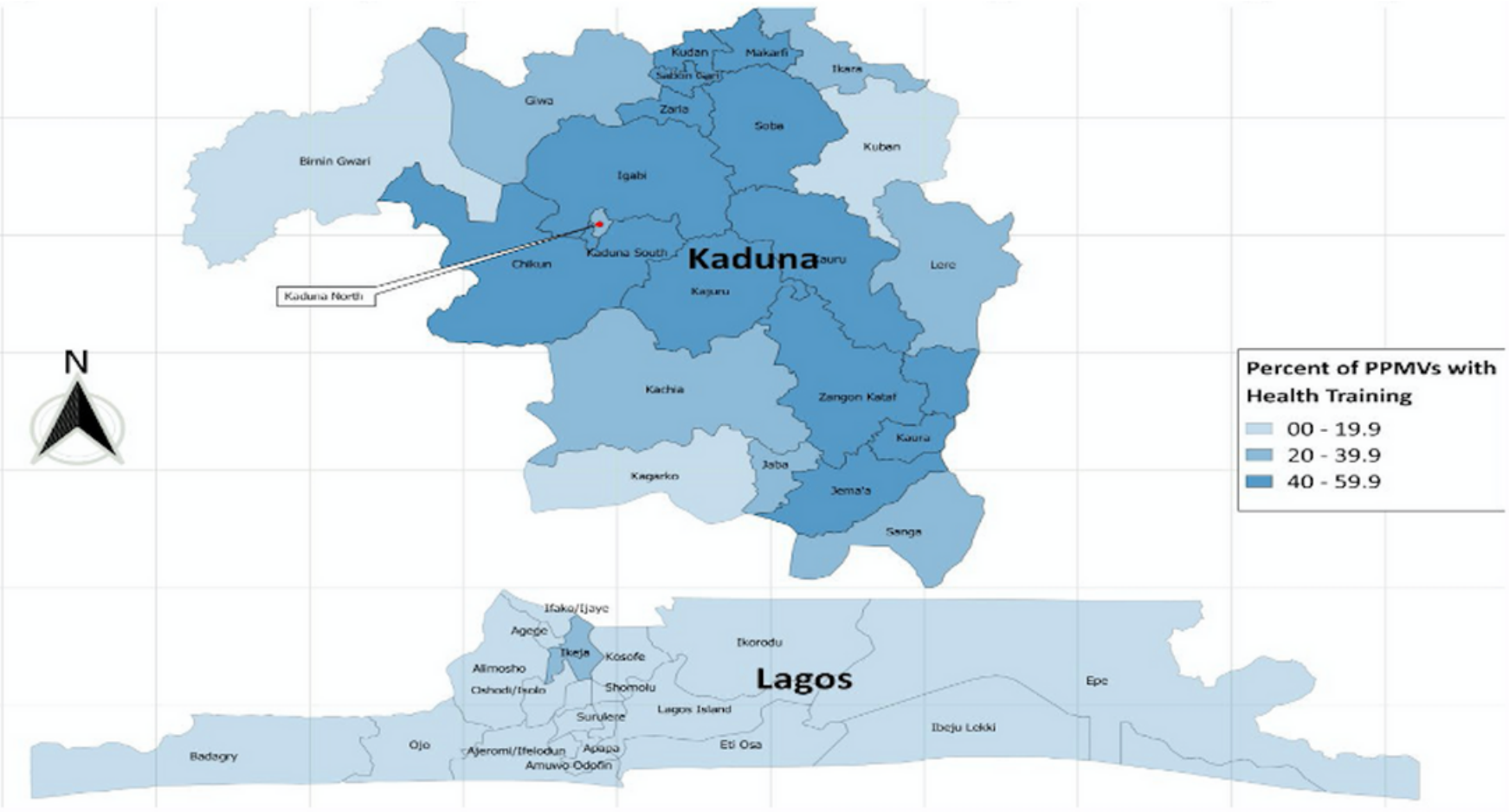

\section{Figure 3}

Proportion of Patent and Proprietary Medicine Vendors with Health Training in Kaduna and Lagos States, 2018 